\title{
PREPARATION AND EVALUATION OF STOMACH SPECIFIC IPN HYDROGELS FOR ORAL DRUG DELIVERY: A REVIEW
}

\author{
Madolia Himi, Sheo Datta Maurya \\ Department of Pharmacy,IEC College of Engineering \& Technology, Greater Noida, India-201308 \\ *Corresponding Author's Email: himi.madolia@gmail.com, 9891246046
}

\begin{abstract}
:
The objective of the present study was to study the potential of hydrogel as a target release system to the stomach. The hydrogel are composed of polyvinyl pyrollidone, poly ( $N$-isopropylacrylamide), chitosan, glutaraldehyde, amoxicillin trihydrate and omeprazole with high mechanical strength and adjustable thermosensitivity. The chemical structure of the polymer may also affect the swelling ratio of hydrogels. They can exhibit dramatic changes in their swelling behavior, network structure, permeability and mechanical strength in response to change in $\mathrm{pH}$ or ionic strength of the surrounding fluid or temperature. Hydrogel are evaluated using high pressure liquid chromatography, FTIR, differential scanning calorimetry, swelling studies, in vitro drug release study, mucoadhesive study and scanning electron microscopy. The assumption is that Interpenetrating Networks (IPN) hydrogels are showing greater swelling and more mucoadhesive in nature, released more drugs at lower $\mathrm{pH}$ values than the higher $\mathrm{pH}$ value.

Keywords: IPN Hydrogel, Chitosan, Crosslinking agent, Glutaraldehyde, stomach specific.
\end{abstract}

\section{INTRODUCTION:}

Hydrogels have been widely used as a drug carrier due to its ease in manufacturing and self application. The production of a large and constant surface area is one of the major merits for them to be widely used for clinical and fundamental applications. Various combinations of polymers are made into hydrogel formulations to investigate their potential as a drug delivery system. The combination of natural and synthetic polymers may provide mechanical stability and biological acceptability, acquiring from synergistic properties of both materials. The hydrogels were found stable and resilient ${ }^{1}$. The existence of hydrogels dates back to 1960, when Wichterle and Lim first proposed the use of hydrophilic networks of poly(2-hydroxyethyl methacrylate) (PHEMA) in contact lenses. ${ }^{2}$ Since then, the use of hydrogels has extended to various biomedical ${ }^{3}$ and pharmaceutical $^{4}$ applications. Antibiotics loaded interpenetrating network hydrogel based on poly(acrylic acid) and glutaradehyde for treatment of experimental $\mathrm{H}$ pylori. IPN hydrogels such as gelatin and dextran are widely used as a drug carrier due to their biodegradability and removable versatility in terms of composition and size.

Hydrogels are three-dimensional, hydrophilic, polymeric networks capable of imbibing large amounts of water or biological fuids. ${ }^{6,7}$ The networks are composed of homopolymers or copolymers, and are insoluble due to the presence of chemical crosslinks (tie-points, junctions), physical crosslinks, such as entanglements or crystallites. ${ }^{8-15}$ The latter provide the network structure and physical integrity. These hydrogels exhibit a thermodynamic compatibility with water which allows them to swell in aqueous media. $6,7,15-16$

There are numerous applications of these hydrogels, in particular in the medical and pharmaceutical sectors. ${ }^{17-18}$ Hydrogels resemble natural living tissue more than any other class of synthetic biomaterials. This is due to their high water contents and soft consistency which is similar to natural tissue. ${ }^{17}$ Furthermore, the high water content of the materials contributes to their biocompatibility. Thus, hydrogels can be used as contact lenses, membranes for biosensors, linings for artificial hearts, materials for artificial skin, and drug delivery devices. ${ }^{17-19}$

Hydrogels are also used as carriers that can interact with the mucosa lining in the gastrointestinal (GI) tract, colon, vagina, nose and other parts of the body due to their ability to prolong their residence time at the delivery location ${ }^{20}$. The interaction between such carriers and the glycoprotein's in the mucosa is thought to occur primarily via hydrogen bonding. Therefore, materials containing a high density of carboxyl and hydroxy groups appear to be promising for this type of application. Monomers most often used for the synthesis of mucoadhesive polymers include acrylic and methacrylic acid (MAA). The idea of adhesion promoters diffusing across the polymer/mucin interface has also been introduced. ${ }^{21}$ Chains of polymerized ethylene glycol either freely loaded in the carrier or grafted to the polymer surface, have been utilized as adhesion promoters. ${ }^{21}$ The 'stealth' properties of poly(ethylene glycol), known also as PEG, have also been used to reduce the uptake of particulate carriers by the reticuloendothelial system. ${ }^{22}$ PEG has also been shown to both lengthen the biological half-life and reduce the immunogenicity of high molecular weight substances, such as adenosine de-aminase (ADA) and asparaginase. $^{23}$

\section{CLASSIFICATION:}

Hydrogels can be classified as neutral or ionic, based on the nature of the side groups. According to their mechanical and structural characteristics, they can be classified as affine or phantom networks. Additionally, they can be homopolymers or copolymer networks, based on the method of preparation. Finally, they can be classified based on the physical structure of the networks as amorphous, semi crystalline, hydrogen-bonded structures, super molecular structures and hydro colloidal aggregates. ${ }^{24-44}$. 
Hydrogels may also show a swelling behavior dependent on the external environment. These polymers are physiologically-responsive hydrogels, where polymer complexes can be broken or the network can be swollen as a result of the changing external environment. These systems tend to show drastic changes in their swelling ratio as a result. Some of the factors affecting the swelling of physiologically-responsive hydrogels include $\mathrm{pH}$, ionic strength, temperature and electromagnetic radiation. ${ }^{45}$

\section{BIOMEDICAL APPLICATIONS OF HYDROGELS:}

Hydrogels are an extremely important class of materials with tremendous application potential in biology and pharmaceutical sciences. Synthetic hydrogels are polymeric networks of hydrophilic groups containing chains that are swollen in water. Polyelectrolyte hydrogels are especially useful as they either carry, or are able to develop charges on the chain. Hydrogels can be designed to exhibit significant volume changes in response to small changes in their environment such as $\mathrm{pH}$, ionic strength, temperature, electric field, solvent, or magnetic field.

Many biological applications of polyelectrolyte's are due to their ability to bind oppositely charged species to form complexes. Recently, numerous studies have utilized cationic systems for gene and antisense therapies and bile acid sequestrates and have devoted to the development of viral and nonviral vectors for DNA and oligonucleotide delivery. ${ }^{46,47}$ Among the synthetic carriers, major attention is paid to cationic polymers which are able to do both condense large structure into smaller ones and mask the negative DNA charges, which is necessary for transfecting most types of cells. A good delivery system should provide resistance to premature enzymatic degradation and aggregation, be able to target specific tissues, cross the cell membrane, facilitate the nuclear uptake, and supply controlled release of the genetic material, while inducing no toxicity or immune response. ${ }^{48}$ For these reasons, suitable coating of delivery system is very important for certain applications. $^{49}$

\section{IPN}

Generally IPNs are created for the purpose of combining individual properties of two or more polymers. In some cases, entirely new properties are exhibited by the IPN that are not observed in either of the two single networks alone. ${ }^{50}$ The development of interpenetrating network polymers is attractive because IPNs provide free volume space for the easy encapsulation of drugs in the three-dimensional network structure which are obtained by cross-linking of two or more polymer network. ${ }^{51}$ Various properties of IPNs such as porosity, bio-adhesiveness, elasticity, swelling and stimuli-responsive behavior can be controlled by the appropriate choice of the network-forming polymers and suitable cross-linking agent and its proportion. ${ }^{64,65}$ These biocompatible, nontoxic and biodegradable polymers are now acquiring unique place for biomedical application for various purposes such as cartilage scaffolds, biological tissue graft, tissue engineering, wound dressing and for drug delivery. ${ }^{52,53,54}$

\section{ANATOMY OF STOMACH:}

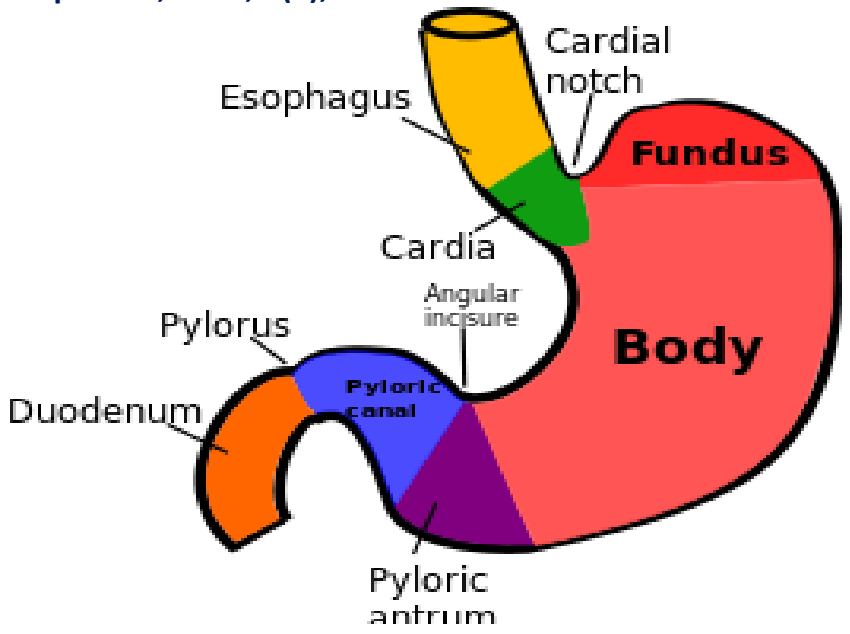

Figure 1: SCHEMATIC DIAGRAM OF STOMACH

(source: http://en.wikipedia.org/wiki/Stomach)

The stomach is located in the upper-left area of the abdomen below the liver and next to the spleen. Its expanded $\mathbf{J}$ shape and three layers of muscle help turn liquid and chewed food into material suitable for the intestinal tract. When the stomach is empty, the inside has small folds called rugae. As the stomach expands, these folds disappear to accommodate the new contents. The average stomach can hold about 1.5 gallons of food and liquid at maximum capacity. It only holds food for about four hours before passing it along the digestive tract. The stomach's main component for digestion is the powerful mix of secretions collectively called gastric juices. To counteract these strong juices, the stomach protects itself with mucus-like secretions. Without this protection, the stomach would essentially digest itself. Cells in the stomach create the active ingredients in gastric juices:

Pepsin: This protein-digesting enzyme activates when food enters the stomach.

Hydrochloric acid: This extremely strong acid breaks down food and any other foreign element such as dirt and bacteria.

Two muscular rings called sphincters also provide additional defense against the chemicals in the stomach by moving contents along. The esophageal sphincter separates the esophagus and the stomach. When that muscle doesn't relax properly, it feels like it is difficult to swallow. On the opposite end of the stomach, the pyloric sphincter regulates the speed at which food moves down to the small intestine.

After the stomach has done its work, the highly acidic mixture of gastric juices and food (known as chyme) leaves the stomach, moves past the pyloric sphincter, and goes into the duodenum before entering the small intestine.

\section{MATERIALS REQUIRED AND METHODS METHOD FOR PREPARATION OF HYDROGEL: ${ }^{55}$}

Cross-linked networks of synthetic polymers such as polyethylene oxide (PEO), polyvinyl pyrollidone (PVP), polylactic acid (PLA), polyacrylic acid (PAA) polymethacrylate (PMA),polyethylene glycol (PEG), or natural biopolymers such as alginate, chitosan, carrageenan, hyaluronan, and carboxymethyl cellulose (CMC) have been reported. The various preparation techniques adopted are physical cross-linking, chemical cross-linking, grafting polymerisation , and radiation cross-linking. Such 
modifications can improve the mechanical properties and viscoelasticity for applications in biomedical and pharmaceutical fields. The general methods to produce physical and chemical gels are described below.

\section{Physical cross-linking}

There has been an increased interest in physical or reversible gels due to relative ease of production and the advantage of not using cross-linking agents. These agents affect the integrity of substances to be entrapped (e.g. cell, proteins, etc.) as well as the need for their removal before application. Careful selection of hydrocolloid type, concentration and $\mathrm{pH}$ can lead to the formation of a broad range of gel textures and is currently an area receiving considerable attention, particularly in the food industry. The various methods reported in literature to obtain physically cross-linked hydrogels are:

\section{a. Heating/cooling a polymer solution}

Physically cross-linked gels are formed when cooling hot solutions of gelatine or carrageenan. The gel formation is due to helix-formation, association of the helices, and forming junction zones. Carrageenan in hot solution above the melting transition temperature is present as random coil conformation. Upon cooling it transforms to rigid helical rods.

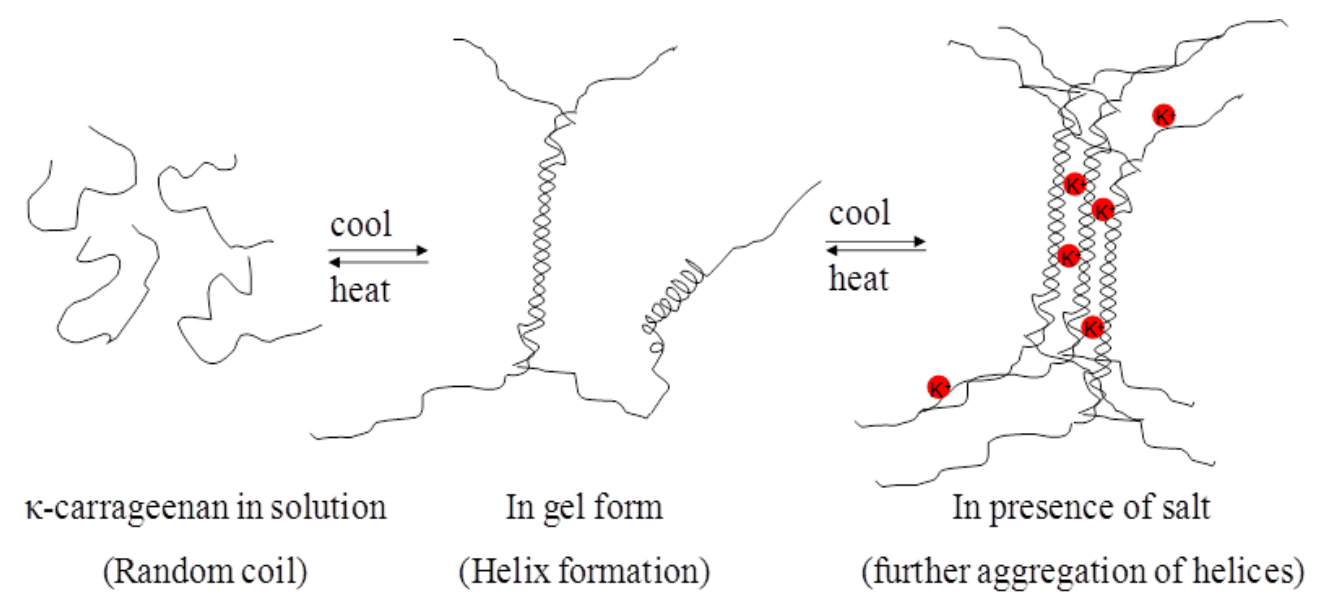

Figure 2: Gel formation due to aggregation of helix upon cooling a hot solution of carrageenan. ${ }^{\text {(Source: }}$ http://cdn.intechopen.com/pdfs/17237/InTech-Hydrogels_methods_of_preparation_characterisation_and_applications.pdf)

In presence of salt $\left(\mathrm{K}^{+}, \mathrm{Na}^{+}\right.$, etc.), due to screening of repulsion of sulphonic group $\left(\mathrm{SO}_{3}^{-}\right)$, double helices further aggregate to form stable gels (Figure 2). In some cases, hydrogel can also be obtained by simply warming the polymer solutions that causes the block copolymerisation. Some of the examples are polyethylene oxidepolypropylene oxide, polyethylene glycol-polylactic acid hydrogel.

\section{b. Ionic interaction}

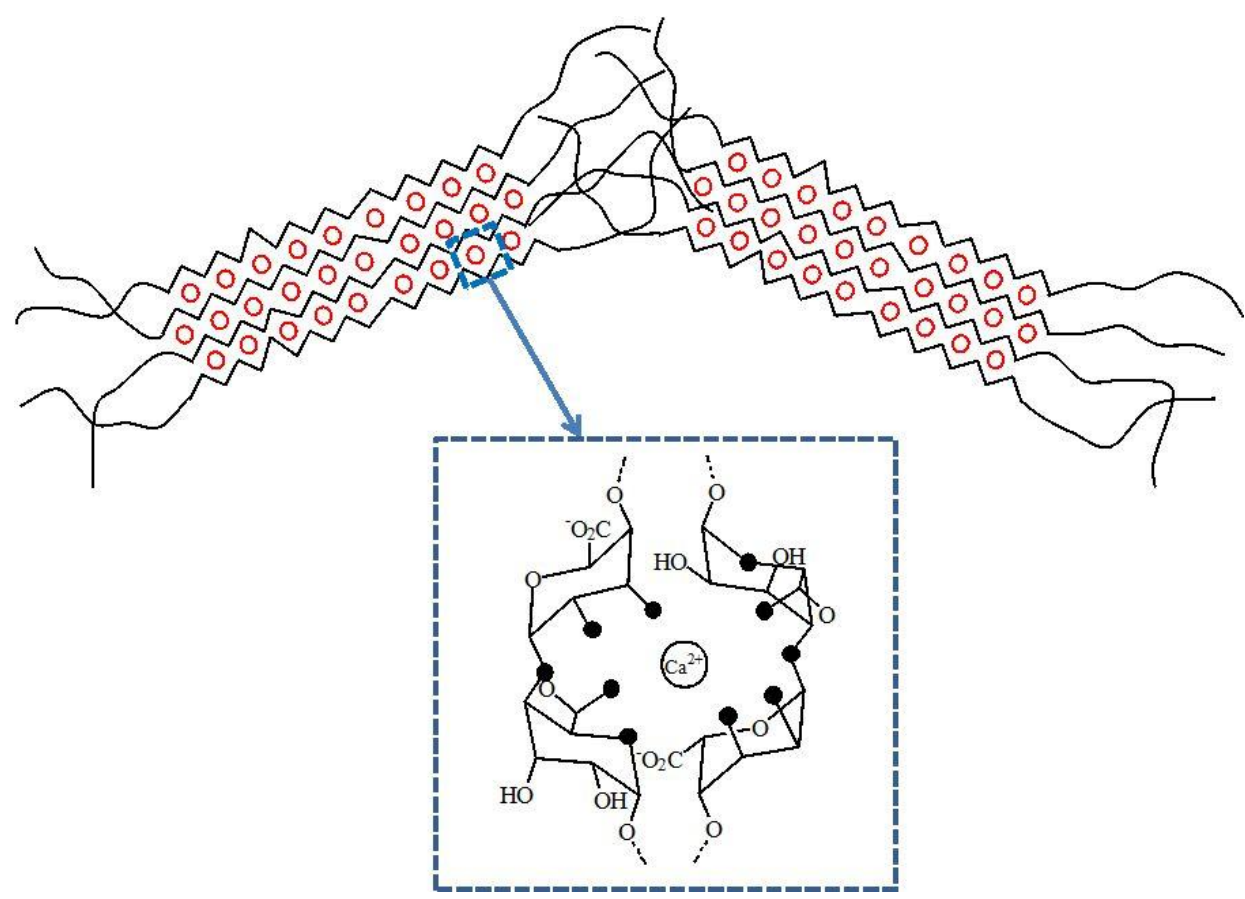

Figure 3: Ionotropic gelation by interaction between anionic groups on alginate $\left(\mathrm{COO}^{-}\right)$with divalent metal ions $\left(\mathrm{Ca}^{2+}\right)$. (Source:http://cdn.intechopen.com/pdfs/17237/InTech-Hydrogels_methods_of_preparation_characterisation_and_applications.pdf) 
Madolia et al

Journal of Drug Delivery 8

Ionic polymers can be cross-linked by the addition of di- or tri-valent counterions. This method underlies the principle of gelling a polyelectrolyte solution (e.g. $\mathrm{Na}^{+}$alginate ${ }^{-}$) with a multivalent ion of opposite charges (e.g. $\mathrm{Ca}^{2+}+2 \mathrm{Cl}^{-}$) (Figure 3 ). Some other examples are chitosan-polylysine, chitosanglycerol phosphate salt, chitosan-dextran hydrogels.

\section{c. Complex coacervation}

Complex coacervate gels can be formed by mixing of a polyanion with a polycation. The underlying principle of this
Therapeutics; 2013, 3(2), 131-140

134

method is that polymers with opposite charges stick together and form soluble and insoluble complexes depending on the concentration and $\mathrm{pH}$ of the respective solutions (Figure 4). One such example is coacervating polyanionic xanthan with polycationic chitosan. Proteins below its isoelectric point are positively charged and likely to associate with anionic hydrocolloids and form polyion complex hydrogel (complex coacervate).

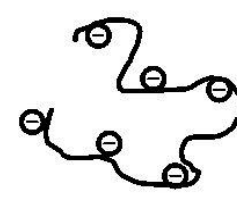

Anionic polymer

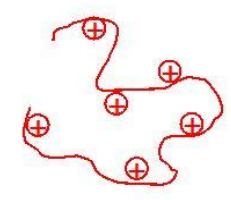

Cationic polymer

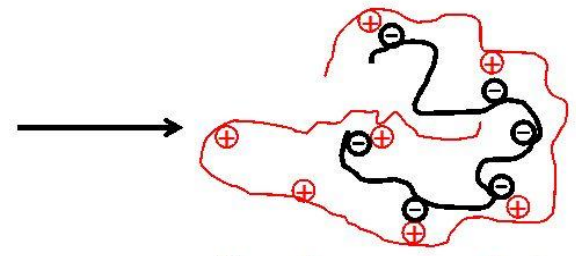

Complex coacervate / polyion complex hydrogel

Figure 4: Complex coacervation between a polyanion and a polycation.

(Source:http://cdn.intechopen.com/pdfs/17237/InTech-Hydrogels_methods_of_preparation_characterisation_and_applications.pdf)

\section{d. H-bonding}

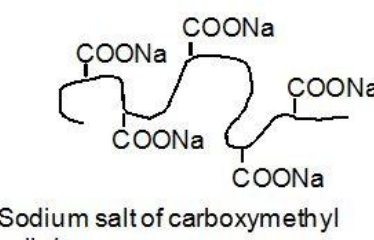
cellulose

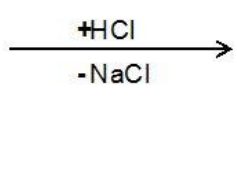

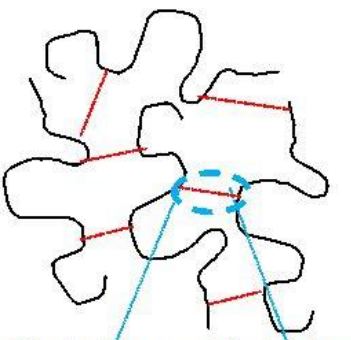

Physically cross-linked network

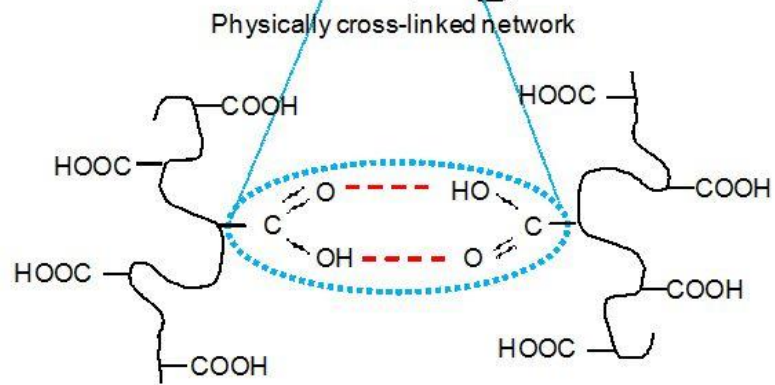

Figure 5: Hydrogel network formation due to intermolecular $\mathrm{H}$-bonding in CMC at low pH.

(Source:http://cdn.intechopen.com/pdfs/17237/InTech-Hydrogels_methods_of_preparation_characterisation_and_applications.pdf)

H-bonded hydrogel can be obtained by lowering the $\mathrm{pH}$ of aqueous solution of polymers carrying carboxyl groups. An example of such hydrogel is a hydrogen-bound CMC (carboxymethyl cellulose) network formed by dispersing $\mathrm{CMC}$ into $0.1 \mathrm{M} \mathrm{HCl}$. The mechanism involves replacing the sodium in CMC with hydrogen in the acid solution to promote hydrogen bonding (Figure 5). The hydrogen bonds induce a decrease of CMC solubility in water and result in the formation of an elastic hydrogel. Carboxymethylated chitosan (CM-chitosan) hydrogels can also prepared by cross-linking in the presence of acids or polyfunctional monomers. Another example is polyacrylic acid and polyethylene oxide (PEO-PAAc) based hydrogel prepared by lowering the $\mathrm{pH}$ to form $\mathrm{H}$-bonded gel in their aqueous solutio. In case of xanthan-alginate mixed system molecular interaction of xanthan and alginate causes the change in matrix structure due to intermolecular hydrogen bonding between them resulting in formation of insoluble hydrogel.

\section{Chemical cross-linking}

Chemical cross-linking covered here involves grafting of monomers on the backbone of the polymers or the use of a cross-linking agent to link two polymer chains. The crosslinking of natural and synthetic polymers can be achieved through the reaction of their functional groups (such as $\mathrm{OH}$, $\mathrm{COOH}$, and $\mathrm{NH}_{2}$ ) with cross-linkers such as aldehyde (e.g. glutaraldehyde, adipic acid dihydrazide). There are a number of methods reported in literature to obtain chemically crosslinked permanent hydrogels. Among other chemical crosslinking methods, IPN (polymerise a monomer within another solid polymer to form interpenetrating network structure) and hydrophobic interactions (incorporating a polar 
hydrophilic group by hydrolysis or oxidation followed by covalent cross-linking) are also used to obtain chemically cross-linked permanent hydrogels. The following section reviews the major chemical methods (i.e. cross-linker, grafting, and radiation in solid and/or aqueous state) used to produce hydrogels from a range of natural polymers.

\section{a. Chemical cross-linkers}

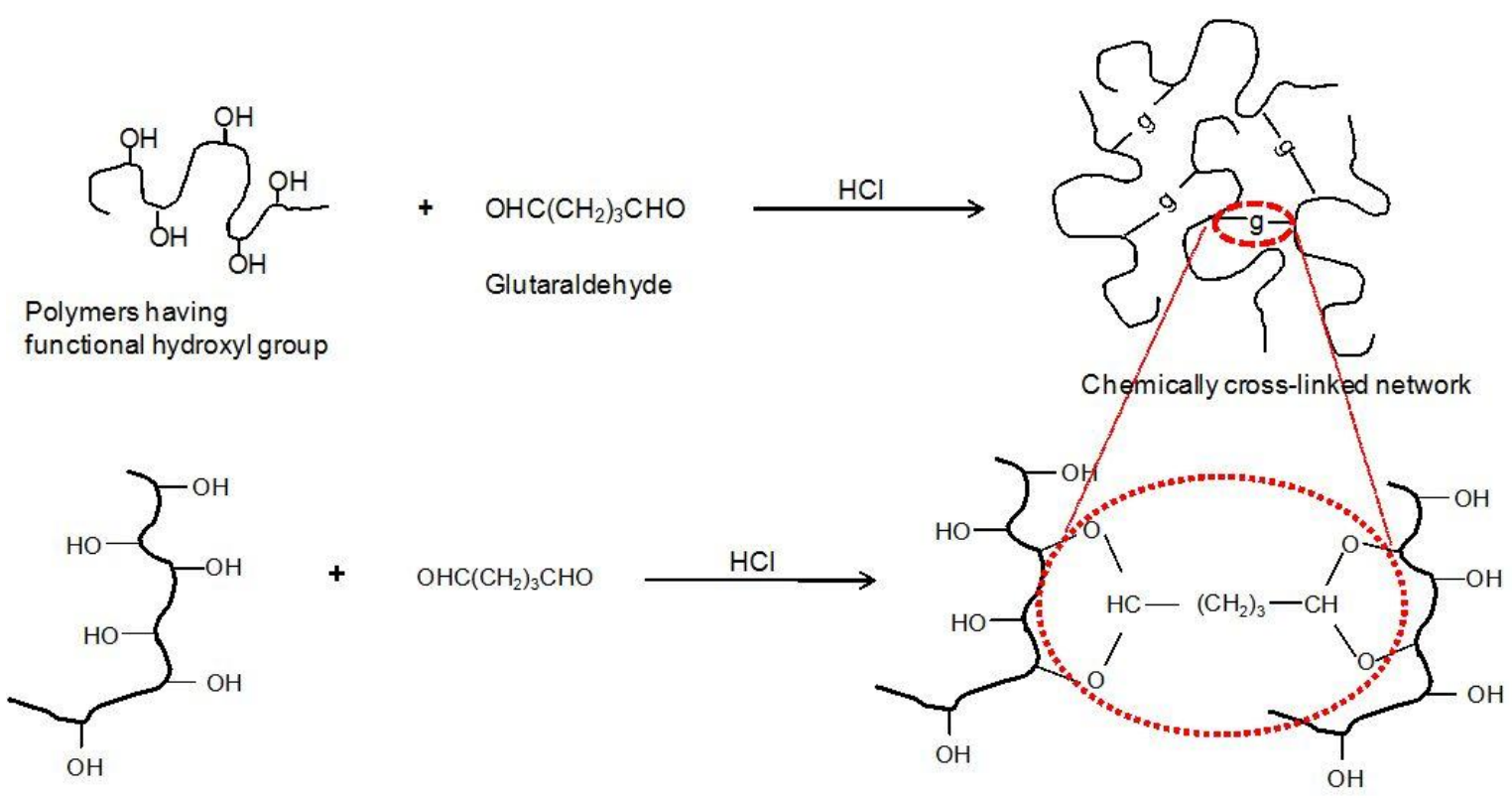

Figure 6: Schematic illustration of using chemical cross-linker to obtain cross-linked hydrogel network.

(Source:http://cdn.intechopen.com/pdfs/17237/InTech-Hydrogels_methods_of_preparation_characterisation_and_applications.pdf)

Cross-linkers such as glutaraldehyde, epichlorohydr, etc have been widely used to obtain the cross-linked hydrogel network of various synthetic and natural polymers. The technique mainly involves the introduction of new molecules between the polymeric chains to produce cross-linked chains (Figure 6). One such example is hydrogel prepared by crosslinking of corn starch and polyvinyl alcohol using glutaraldehyde as a cross-linker. The prepared hydrogel membrane could be used as artificial skin and at the same time various nutrients/healing factors and medicaments can be delivered to the site of action.CMC chains can also be cross-linked by incorporating 1, 3-diaminopropane to produce CMC-hydrogel suitable for drug delivery through the pores. Hydrogel composites based on xanthan and polyvinyl alcohol cross-linked with epichlorohydrin in another example. $\kappa$-carrageenan and acrylic acid can be cross-linked using 2-acrylamido-2-methylpropanesulfonic acid leading to the development of biodegradable hydrogels with proposed use for novel drug delivery systems. Carrageenan hydrogels are also promising for industrial immobilisation of enzymes. Hydrogels can also be synthesized from cellulose in $\mathrm{NaOH} /$ urea aqueous solutions by using epichlorohydrin as cross-linker and by heating and freezing methods.

\section{b. Grafting}

Grafting involves the polymerisation of a monomer on the backbone of a preformed polymer. The polymer chains are activated by the action of chemical reagents, or high energy radiation treatment. The growth of functional monomers on activated macroradicals leads to branching and further to cross-linking (Figure 7).

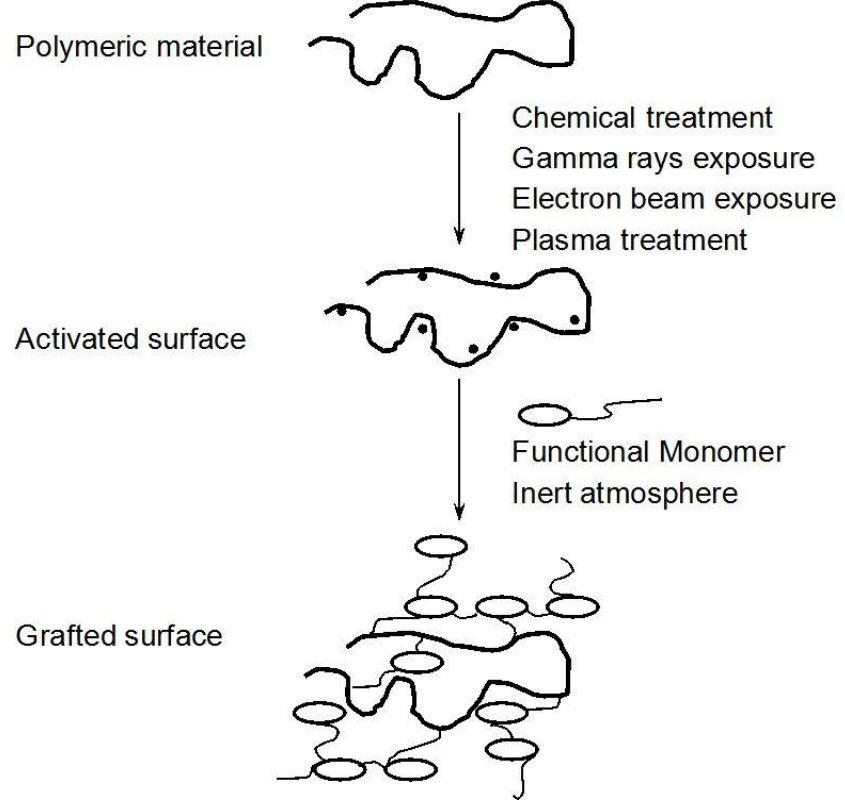

Figure 7: Grafting of a monomer on preformed polymeric backbone leading to infinite branching and cross-linking.

(Source:http://cdn.intechopen.com/pdfs/17237/InTech-

Hydrogels_methods_of_preparation_characterisation_and_applications.pdf)

\section{i. Chemical grafting}

In this type of grafting, macromolecular backbones are activated by the action of a chemical reagent. Starch grafted with acrylic acid by using $\mathrm{N}$-vinyl-2-pyrrolidone is an example of this kind of process Such hydrogels show an excellent $\mathrm{pH}$-dependent swelling behaviour and possess ideal characteristic to be used as drug and vitamin delivery device in the small intestine. 


\section{ii. Radiation grafting}

Grafting can also be initiated by the use of high energy radiation such as gamma and electron beam. Said, Alla et al. (2004) reported the preparation of hydrogel of CMC by grafting CMC with acrylic acid in presence of electron beam irradiation, in aqueous solution. Electron beam was used to initiate the free radical polymerisation of acrylic acid on the backbone of CMC. Water radiolysis product will also be helpful to abstract proton form macromolecular backbones. Irradiation of both (CMC and monomer) will produce free radicals that can combine to produce hydrogel. They proposed the application of such acrylic acid based hydrogel for the recovery of metal ions like copper, nickel, cobalt, and lead. Also, they reported the application of hydrogels in dressings for temporary skin covers.

\section{Radiation cross-linking}

Radiation cross-linking is widely used technique since it does not involve the use of chemical additives and therefore retaining the biocompatibility of the biopolymer. Also, the modification and sterilisation can be achieved in single step and hence it is a cost effective process to modify biopolymers having their end-use specifically in biomedical application. The technique mainly relies on producing free radicals in the polymer following the exposure to the high energy source such as gamma ray, x-ray or electron beam. The action of radiation (direct or indirect) will depend on the polymer environment (i.e. dilute solution, concentrated solution,

state).

Table1: Polymers and Crosslinkers Used in Composition of IPN Hydrogels

\begin{tabular}{|l|l|l|l|}
\hline Polymers & Crosslinkers & Biomedical Applications & Ref \\
\hline Poly vinyl pyrollidone & GA & Controlled release of amoxicillin and omeprazole & 56 \\
\hline Poly bismethyl acryl amide & GA & Oral controlled release of drug & 57 \\
\hline Polyethylene glycol & GA & Oral controlled release of omeprazole & 58 \\
\hline Poly(N-isopropyl acrylamide) & MBA & Oral pH, temperature sensitive release & 59 \\
\hline
\end{tabular}

\section{PROPERTIES OF CHITOSAN}

Chitosan is a polysaccharide that is obtained by alkaline deacetylation of a naturally occurring polysaccharide, chitin. Chitin occurs abundantly in nature as ordered crystalline micro fibrils forming structural components in the exoskeleton of arthropods or in the cell walls of fungi and yeast.

Production of chitosan from these sources is inexpensive and easy. Chitosan is a linear co-polymer polysaccharide consisting of $\beta$ (1-4)-linked 2-amino-2-deoxy-D-glucose (Dglucosamine) and 2-acetamido-2-deoxy-D-glucose (Nacetyl-D-glucosamine) units. ${ }^{60}$

\section{Chitosan}

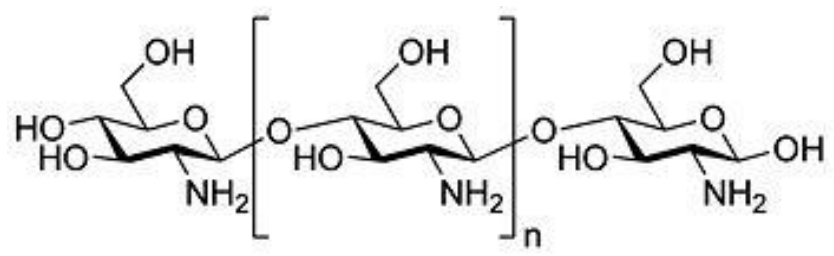

Figure 8: Structure of Chitosan

Chemically chitosan is poly[ $\beta$-(1-4)-2-amino-2-deoxy-Dglucopyranose]. It is an interesting polysaccharide primarily due to the presence of the amino functionality, which could be suitably modified to impart desired properties and distinctive biological functions including solubility and bioadhesivity ${ }^{61}$ Properties of chitosan depends on a number of parameters such as the molecular weight, degree of deacetylation sequence of the amino group (D-glucosamine residues) and the acetamido groups (N-acetyl-Dglucosamine) and the purity of the product. Chitosan is metabolized by certain human enzymes, especially lysozyme, and is considered biodegradable. ${ }^{62}$
It is also biocompatible, non-immunogenic, noncarcinogenic, nontoxic and mucoadhesive polymer, which makes it a suitable candidate for biomedical applications, such as wound management, tissue engineering and drug delivery vehicle. ${ }^{63-68}$ Chitosan also shows permeation enhancer properties and it is able to enhance the paracellular route of absorption, which is important for the transport of hydrophilic compounds such as therapeutic peptides and antisense oligonucleotide across the membrane. ${ }^{69-71}$

\section{PROPERTIES OF GLUTARALDEHYDE}

Glutaraldehyde is an organic compound with the formula $\mathrm{CH}_{2}\left(\mathrm{CH}_{2} \mathrm{CHO}\right)_{2}$. A pungent colorless oily liquid, glutaraldehyde is used to disinfect medical and dental equipment. It is also used for industrial water treatment and as a preservative. It is mainly available as an aqueous solution, and in these solutions the aldehyde groups are hydrated. $^{72}$

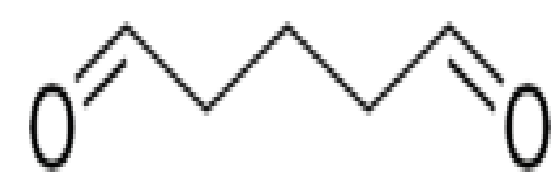

Figure 9: Structure of Glutaraldehyde

Glutaraldehyde is a colorless liquid with a pungent odor used to sterilize medical and dental equipment. It is also used for industrial water treatment and as a chemical preservative. However, it is toxic, causing severe eye, nose, throat and lung irritation, along with headaches, drowsiness and dizziness.

Glutaraldehyde is an oily liquid at room temperature (density $1.06 \mathrm{~g} / \mathrm{mL}$ ), and miscible with water, alcohol, and benzene. It is used as a tissue fixative in electron 
microscopy. It is employed as embalming fluid, is a component of leather tanning solutions, and occurs as an intermediate in the production of certain industrial chemicals.

\section{Methods of cross linking}

Several techniques have been reported for the synthesis of hydrogels. The first approach involves copolymerization/cross linking of co-monomers using multifunctional co-monomer, which acts as cross linking agent. The polymerization reaction is initiated by chemical initiator. The polymerization reaction can be carried out in bulk, in solution, or in suspension. The second method involves cross linking of linear polymers by irradiation, or by chemical compounds. ${ }^{73}$ The monomers used in the preparation of the ionic polymer network contain an ionizable group, a group that can be ionized, or a group that can undergo a substitution reaction after the polymerization is completed. As a result, hydrogels synthesized contain weakly acidic groups like carboxylic acids, or a weakly basic group like substituted amines, or a strong acidic and basic group like sulfonic acids, and quaternary ammonium compounds. Some of the commonly used crosslinking agents include $\mathrm{N}, \mathrm{N}$-methylenebisacrylamide, divinyl benzene, and ethylene glycol dimethacrylate.

\section{Solution polymerization/cross linking:}

In solution, co-polymerization/cross linking reactions, and ionic or neutral monomers are mixed with the multifunctional cross linking agent. The polymerization is initiated thermally, by UV-light, or by redox initiator system. The presence of solvent serves as heat sink, and minimizes temperature control problems. The prepared hydrogels need to be washed with distilled water to remove the unreacted monomers, crosslinking agent, and the initiator. The best example is preparation of poly(2hydroxyethyl methacrylate) ${ }^{74}$ hydrogels from hydroxyethyl methacrylate, using ethylene glycol dimethacrylate as crosslinking agent. Using the above method, a great variety of hydrogels have been synthesized. ${ }^{75}$ The hydrogels can be made $\mathrm{pH}$ - sensitive or temperature-sensitive, by incorporating methacrylic acid, $^{76}$ or $\mathrm{N}$ isopropylacrylamide ${ }^{77}$ as monomers.

\section{Suspension polymerization:}

This method is employed to prepare spherical hydrogel microparticles with size range of $1 \mu \mathrm{m}$ to $1 \mathrm{~mm}$. In suspension polymerization, the monomer solution is dispersed in the non-solvent forming fine droplets, which are stabilized by the addition of stabilizer. The polymerization is initiated by thermal decomposition of free radicals. The prepared microparticles then washed to remove unreacted monomers, cross linking agent, and initiator. Hydrogel microparticles of poly(vinyl alcohol) and poly(hydroxy ethyl methacrylate) have been prepared by this method.

\section{Polymerization by irradiation:}

High energy radiation like gamma and electron beam, have been used to prepare the hydrogels of unsaturated compounds. The irradiation of aqueous polymer solution results in the formation of radicals on the polymer chains. Also, radiolysis of water molecules results in the formation hydroxyl radicals, which also attack the polymer chains, resulting in the formation of macroradicals. Recombination of the macroradicals on different chains results in the formation of covalent bonds, and finally a crosslinked structure is formed. ${ }^{78}$ During radiation, polymerization macroradicals can interact with oxygen, and as a result, radiation is performed in an inert atmosphere using nitrogen or argon gas. Examples of polymers crosslinked by radiation method include poly(vinyl alcohol) $)^{79}$, poly (ethylene glycol), ${ }^{80,81,82}$ poly(acrylic acid). ${ }^{83}$ The major advantage over chemical initiation is the production of relatively pure, residue-freehydrogels.

\section{Chemically crosslinked hydrogels:}

Polymers containing functional groups like - $\mathrm{OH},-\mathrm{COOH}$, $\mathrm{NH}_{2}$, are soluble in water. The presence of these functional groups on the polymer chain, can be used to prepare hydrogels by forming covalent linkages between the polymer chains and complementary reactivity, such as amine-carboxylic acid, isocyanate- $\mathrm{OH} / \mathrm{NH}_{2}$ or by Schiff base formation. ${ }^{84}$

Gluteraldehyde can be used as a crosslinking agent to prepare hydrogels of polymers containing - $\mathrm{OH}$ groups like poly(vinyl alcohol). ${ }^{85}$ Also, polymers containing amine groups (albumin, gelatin, polysaccharides) $)^{86,87,88,89}$ can be crosslinked using glutaraldehyde.

Polymers that are water soluble, can be converted to hydrogels, using bis or higher functional crosslinking agents like divinylsulfone ${ }^{90}$ and 1,6-hexanedibromide. The crosslinking agents react with the functional groups present on the polymer, via addition reaction. These crosslinking agents are highly toxic, and hence unreacted agents have to be extracted. Moreover the reaction has to be carried out in organic solvent, as water can react with the crosslinking agent. The drugs have to be loaded after the hydrogels are formed, as a result the release will be typically first order.

Crosslinking between polymers through hydrogen bond formation occur as in the case of poly(methacrylic acid) and poly(ethylene glycol). The hydrogen bond formation takes place between the oxygen of poly(ethylene glycol) and carboxylic acid group of poly(methacrylic acid). Carriers consisting of networks of poly(methacrylic acid-g-ethylene glycol) showed $\mathrm{pH}$ dependent swelling due to the reversible formation of interpolymer complex, stabilized by hydrogen bonding between the etheric groups of the grafted poly(ethylene glycol), and the carboxylic acid protons of the poly(methacrylic

\section{Physically crosslinked hydrogels:}

Most of the covalent crosslinking agents are known to be toxic, even in small traces. A method to overcome this problem and to avoid a purification step, is to prepare hydrogels by reversible ionic crosslinking. Chitosan, a polycationic polymer can react with positively charged components, either ions or molecules, forming a network through ionic bridges between the polymeric chains. Among anionic molecules, phosphate bearing groups, particularly sodium tripolyphosphate is widely studied. Ionic crosslinking is a simple and mild procedure. In contrast to covalent crosslinking, no auxiliary molecules such as catalysts are required. ${ }^{91}$ Chitosan is also known to form polyelectrolyte complex with poly(acrylic acid). The polyelectrolyte complex undergoes slow erosion, which gives a more biodegradable material than covalently crosslinked hydrogels. ${ }^{92,93}$ 


\section{Madolia et al CHARACTERIZATION OF HYDROGELS:}

\section{Morphological characterization}

Hydrogels are characterized for morphology which is analyzed by equipment like stereomicroscope. Also the texture of these biomaterials is analyzed by SEM (Scanning Electron Microscope) to ensure that hydrogels, especially of starch, retain their granular structures.

\section{Fourier Transform Infrared Spectroscopy(FTIR) analysis}

FTIR spectra of hydrogel are recorded using FTIR spectrophotometer to determine their structure and intermolecular interactions. Thoroughly ground IPN samples are mixed with dried $\mathrm{KBr}$ and discs are be prepared by compression under vacuum. Spectra are recorded with a resolution of $1 \mathrm{~cm}^{-1}$.

\section{Swelling Studies of IPN hydrogel}

The swelling studies of IPN hydrogel are studied by placing a known weight of hydrogels in $0.1 \mathrm{~N} \mathrm{HCl}$ at $37^{0} \mathrm{C}$. During swelling the gels are removed every $1 \mathrm{hr}$ interval and their surface are dried and filter paper weight are recorded. The swelling process are characterized by following relationship:

\section{Swelling ratio $\%=\mathrm{Ws}-\mathrm{Wd} / \mathrm{Wd} * \mathbf{1 0 0}$,}

where

$$
\begin{aligned}
& \text { Ws- Weight of swollen hydrogels } \\
& \text { Wd- weight of dry hydrogels }
\end{aligned}
$$

\section{Improving the delivery of hydrogels:}

The goal of drug delivery is to maintain the drug concentration in the body (plasma) within therapeutic limits for long periods of time. However, the high water content of most hydrogels results in relatively rapid release of drugs from the gel matrix, particularly in the case of hydrophilic drugs for which hydrogel delivery is typically applied. In this context, a range of strategies have been explored to reduce the release rate of drug from hydrogels either by enhancing the interactions between the drug and the hydrogel matrix and/or by increasing the diffusive barrier to drug release from the hydrogel. Both physical (charge interaction between polymer and the ionic drug) and chemical (by covalent linking of drug to polymer by using cleavable linkers) ${ }^{94}$ means have been employed to enhance the interaction between a loaded drug and the hydrogel matrix to extend the duration of drug release.

\section{REFERENCES}

1. Suri S, Christine E, Schmidt. Photopatterned collagen-hyaluronic acid interpenetrating polymer network hydrogels. Acta Biomaterialia. 2009; 5: 2385-2397.

2. Wichterle, O. and Lim, D. 1960 Hydrophilic gels for biological use. Nature 185, 117-118

3. Hoffman, A.S. 2002 Hydrogels for biomedical applications. Adv. Drug Deliv. Rev. 54, 3-12

4. Peppas, N.A. et al. 2000 Hydrogels in pharmaceutical formulations. Eur. J. Pharm. Biopharm. 50, 27-46

5. Kosmala DB, Jacqueline D, Henthorn, Peppas Preparation of interpenetrating networks of gelatin and dextran as degradable biomaterials. Biomaterials. 2000; 21, 2019-2023.

6. Mikos A.G., Preparation methods and structure of hydrogels, in: N.A. Peppas (Ed.), Hydrogels in Medicine and Pharmacy, Vol. 1, CRC Press, Boca Raton, FL, 1986, pp. 1-27.
Another approach is to control the diffusion of drugs out of hydrogel matrices by modifying the microstructure of the hydrogel. For modifying the microstructure of hydrogels, interpenetrating polymer network (IPN) ${ }^{95}$ and semi interpenetrating polymer network (semi IPN) ${ }^{96}$ have been used in preference to homopolymers with high concentration of cross-linking agent.

A relatively improved method has been the incorporation of particulate systems (microspheres, liposomes, micro emulsions, micelles, microgel etc.) into the hydrogel matrix to form composite or "plum pudding", hydrogel networks.

\section{CONCLUSION:}

Preparation of hydrogel-based drug product involves either cross-linking of linear polymers or simultaneous polymerization of monofunctional monomers and crosslinking with polyfunctional monomers. Further, the mechanical strength of poorly cross-linked hydrogels can be adequately enhanced by various methods. Polymers from natural, synthetic or semi-synthetic sources can be used for synthesizing hydrogels. In comparison to other synthetic biomaterials, hydrogels resemble living tissues closely in their physical properties because of their relatively high water content and soft and rubbery consistency. Hydrogels show minimal tendency to adsorb proteins from body fluids because of their low interfacial tension. Further, the ability of molecules of different sizes to diffuse into (drug loading) and out of (drug release) hydrogels allows the possible use of dry or swollen polymeric networks as drug delivery systems for oral, nasal, buccal, rectal, vaginal, ocular and parenteral routes of administration.

\section{FUTURE PROSPECTIVE:}

The hydrogels prepared are stomach specific but many opportunities remain to be explored for better use of biomaterials. There is no doubt that many applications can benefit the design of target release drug delivery. Every drug delivery design responds differently to stimuli and can prove to be beneficial. Despite many advances, numerous challenges and opportunities remain for making an impact in the field of hydrogels.

\section{ACKNOWLEDGEMENT:}

The author would like to thank the staff of Department of Pharmacy of IEC-CET, Gr. Noida affiliated Mahamaya Technical University, Noida, Uttar Pradesh for their technical advices.

7. Brannon L Preparation and characterization of crosslinked hydrophilic networks, Harland R.S. (Eds.), Absorbent Polymer Technology, Elsevier, Amsterdam, 1990, pp. 45-66.

8. Peppas, N.A, PVA hydrogels: reinforcement of radiationcrosslinked networks by crystallization, J. Polym. Sci. Polym.Chem. Ed. 14, 1976, 441-457.

9. Merrill EW et al., Differential scanning calorimetry of crystallized PVA hydrogels, J. Appl. Polym. Sci. 20, 1976, 1457-1465.

10. Hydrogels of poly(vinyl alcohol) and its copolymers,in: N.A. Peppas (Ed.), Hydrogels in Medicine and Pharmacy, Vol. 2, CRC Press, Boca Raton, FL, 1986, pp. 1-48.

11. Stauffer S.R et al., Poly(vinyl alcohol) hydrogels preparedby freezing thawing cyclic processing, Polymer, 1992, 33, 3932-3936.

12. Hickey AS, et al., Mesh size and diffusive characteristics of semicrystalline poly(vinyl alcohol) membranes prepared by freezing/ thawing techniques, J. Membr. Sci. 107, 1995, 229-237. 
13. Mongia NK, Ultrapure poly(vinyl alcohol) hydrogels with mucoadhesive drug delivery characteristics, Eur. J. Pharm.Biopharm. 43, 1997, 51-58.

14. Rehner J., Statistical mechanics of cross-linked polymer networks. II. Swelling, J. Chem. Phys. 11 1943, 521-526.

15. Flory P.J., Statistical mechanics of swelling of network structures, J. Chem. Phys. 18, 1950, 108-111.

16. Flory P.J., Principles of Polymer Chemistry, Cornell University Press, Ithaca, NY, 1953.

17. Ratner B.D, Hoffman A.S., Synthetic hydrogels for biomedical applications, in: J.D. Andrade (Ed.), Hydrogels for Medical and Related Applications, ACS Symposium Series, No. 31, American Chemical Society, Washington, DC, 1976, pp. 1-36.

18. Peppas N.A., Hydrogels in Medicine, CRS Press, Boca Raton, FL, 1986.

19. Langer R., New challenges in biomaterials, Science 263,1994, 1715 1720.

20. Huang Y., Leobandung W., Foss A., N.A. Molecular aspects of ucoand bio-adhesion: tethered structures and site-specific surfaces, J. Control. Release 2000 in press.

21. Sahlin J.J., Hydrogels as mucoadhesive and bioadhesive materials: a review, Biomaterials 17, 1996, 1553-1561.

22. Stolnik S., Illum L., Davis S.S., Long circulating microparticulate drug carriers, Adv. Drug Deliv. Rev. 16,1995, 195-214.

23. Burnham N.L, Polymers for delivering peptides and proteins, Am. J. Hosp. Pharm. 51, 1994, 210-218.

24. Mikos ., A.G, Preparation methods and structure of hydrogels, in: N.A. Peppas (Ed.), Hydrogels in Medicine and Pharmacy, Vol. 1, CRC Press, Boca Raton, FL, 1986, pp. 1-27.

25. Brannon L. -Peppas, Preparation and characterization of crosslinked hydrophilic networks, in: L. Brannon-Peppas, R.S. Harland (Eds.), Absorbent Polymer Technology, Elsevier, Amsterdam, 1990, pp. 4566.

26. Merrill E.W., PVA hydrogels: reinforcement of radiationcrosslinked networks by crystallization, J. Polym. Sci. Polym.Chem. Ed. 14, 1976, 441-457.

27. Peppas N.A., Merrill E.W., Differential scanning calorimetry of crystallized PVA hydrogels, J. Appl. Polym. Sci. 20, 1976, 1457 1465.

28. Peppas N.A., Hydrogels of poly(vinyl alcohol) and its copolymers,in: N.A. Peppas (Ed.), Hydrogels in Medicine and Pharmacy, Vol. 2, CRC Press, Boca Raton, FL, 1986, pp. 1-48.

29. Stauffer S.R., Peppas N.A., Poly(vinyl alcohol) hydrogels preparedby freezing \pm thawing cyclic processing, Polymer 33, 1992, 3932-3936.

30. Hickey A.S., Peppas N.A, Mesh size and diffusive characteristics of semicrystalline poly(vinyl alcohol) membranes prepared by freezing/ thawing techniques, J. Membr. Sci. 107, 1995, 229-237.

31. Mongia N.K., Ultrapure poly(vinyl alcohol) hydrogels with mucoadhesive drug delivery characteristics, Eur. J. Pharm.Biopharm. 43, 1997, 51-58.

32. Flory P.J., Rehner J., Statistical mechanics of cross-linked polymer networks. II. Swelling, J. Chem. Phys. 11, 1943, 521-526.

33. Flory P.J., Statistical mechanics of swelling of network structures, J. Chem. Phys. 18, 1950, 108-111.

34. Flory P.J., Principles of Polymer Chemistry, Cornell University Press, Ithaca, NY, 1953.

35. Ratner B.D., Hoffman A.S., Synthetic hydrogels for biomedical applications, in: J.D. Andrade (Ed.), Hydrogels for Medical and Related Applications, ACS Symposium Series, No. 31, American Chemical Society, Washington, DC, 1976, pp. 1-36.

36. Peppas N.A., Hydrogels in Medicine, CRS Press, Boca Raton, FL, 1986.

37. Langer R., New challenges in biomaterials, Science 263, 1994, 1715720.

38. Park K., Controlled Release: Challenges and Strategies, American Chemical Society, Washington, DC, 1997.

39. Peppas N.A., Hydrogels and drug delivery, Curr. Opin. Coll. Int. Sci. $2,1997,531-537$

40. Kabanov V.A., I.M. Papisov, Formation of complexes between complementary synthetic polymers and oligomers in dilute solution, Vysokolmol. Soedin. A21, 1979, 243-281.

41. Bekturov E.A., L.A. Bimendina, Interpolymer complexes, Adv. Polym. Sci. 43, 1981, 100-147.

42. Tsuchida E., K. Abe, Interactions between macromolecules in solution and intermacromolecular complexes, Adv. Polym. Sci. 45, 1982, 1-119.

43. Klier J., N.A. Peppas, Structure and swelling behavior of poly(ethylene glycol)/poly(methacrylic acid) complexes, in: L. Brannon- Peppas, R.S. Harland (Eds.), Absorbent Polymer Technology, Elsevier, Amsterdam, 1990, pp. 147-169.
44. C.L. Bell, N.A. Peppas, Biomedical membranes from hydrogels and interpolymer complexes, Adv. Polym. Sci. 122 (1995) 125-175.

45. Peppas N.A. , Physiologically responsive gels, J. Bioact. Compat. Polym. 6 (1991) 241-246.

46. Vladimir GS, Olga AN, Olga AP, Anatoly AZ, Valentina BR, Alexander BZ, Kenichi Y, Victor AK (2002) J Am Chem Soc 124:11324

47. Rosso AB, Barbarisi M, Petillo O, Margarucci S, Calarco A, Peluso G 2003 Mater Sci Eng C 23:371

48. Giammona G, Cavallaro G, Pitaressi G, Pedone E (2000) Colloid Polym Sci 278:69

49. Sergey K, Marian K, Iwao T, Kalle L 2002 Macromolecules 35:1911

50. Ekici S, Saraydin D; Interpenetrating polymeric network hydrogels for potential gastrointestinal drug release. Polym Int. 2007; 56:13711377

51. Ortega A, Bucio E, Burillo G; New Interpenetrating polymer networks of $\mathrm{N}$-isopropylacrylamide/ N-acryloxysuccinimide: synthesis and characterization. Polym Bull. 2008; 60:515-524.

52. Lumelsky Y, Zoldan J, Levenberg S, Silverstein M S; Porous polycaprolactone-polystyrene semi-interpenetrating polymer networks synthesized within high internal phase emulsions. Macromolecules. 2008; 41:1469-1474.

53. Kim I Y, Yoo M K, Kim B C, Kim S K, Lee H C, Choa C S; Preparation of semi-interpenetrating polymer networks composed of chitosan and poloxamer. Intl J Biol Macromol. 2006; 38:51-58.

54. Angadi S C, Manjeshwar L S, Aminabhavi T M; Interpenetrating polymer network blend microspheres of chitosan and hydroxyethyl cellulose for controlled release of isoniazid. Int J Biol Macromol. 2010; 47: 171-179.

55. Kim, B Flamme, K. L. \& Peppes NA, J Appl. Poly science 2003, 89, 1606

56. Syed K. H. Gulrez, Saphwan Al-Assaf and Glyn O Phillips DOI: $10.5772 / 24553$

57. Risbud M V, Hardikar A A, Bhat S V, Bhonde R R; pH-sensitive freeze-dried chitosan-polyvinyl pyrrolidone hydrogels as controlled release system for antibiotic delivery. J Control Rel. 2000; 68:23-30.

58. Babu V R, Hosamani K M, Aminabhavi T M; Preparation and invitro release of chlorothiazide novel $\mathrm{pH}$-sensitive chitosan-N,N'dimethylacrylamide semi-interpenetrating network microspheres. Carbohydr Polym. 2008; 71:208-217.

59. Gupta K C, Ravikumar MNV; Studies on Semi-Interpenetrating Polymer Network Beads of Chitosan-Poly(ethylene glycol) for the Controlled Release of Drugs. J Appl Polym Sci. 2001; 80:639-649.

60. Chen X, Song H, Fang T, Bai J, Xiong J, Ying H; Preparation, Characterization, and Drug-Release Properties of $\mathrm{pH} / \mathrm{Temperature-}$ Responsive Poly(N-isopropylacrylamide)/Chitosan Semi-IPN Hydrogel Particles. J Appl Polym Sci. 2010; 116:1342-1347.

61. Kumar M N V; A review of chitin and chitosan applications. Reactive \& Functional Polymers. 2000; 46:1-27.

62. Rinaudo M; Chitin and chitosan: properties and applications. Prog Polym Sci. 2006; 31:603-32.

63. Raafat D, Sahl H G; Chitosan and its antimicrobial potential - a critical literature survey. Microbial Biotechnology. 2009; 2(2):186201 .

64. Kean T, Thanou M; Biodegradation, biodistribution and toxicity of Chitosan. Adv Drug Del Rev. 2010; 62:3-11.

65. Honarkar H, Barikani M. Applications of biopolymers I: chitosan Monatsh Chem. 2009; 140:1403-1420.

66. Peniche C, Argu“elles-Monal W, Peniche H, Acosta N. Chitosan: An attractive biocompatible polymer for microencapsulation. Macromol Biosci. 2003; 3:511-520

67. Mia F L, Sung H W, Shyu S S, Sua C C, Peng C K; Synthesis and characterization of biodegradable TPP/genipin cocrosslinked chitosan gel beads. Polymer. 2003; 44:6521-6530.

68. Ylitalo R, Lehtinen S, Wuolijoki E, Ylitalo $\mathrm{P}$, Lehtimäki $\mathrm{T}$, Cholesterol-lowering properties and safety of chitosan. Arzneim Forsch. 2002; 52:1-7.

69. Hamman J H, Kotze' A F; Paracellular absorption enhancement across intestinal epithelia by $\mathrm{N}$-trimethyl chitosan chloride. In: Muzzarelli RAA, Muzzarelli C, eds. Chitosan in pharmacy and chemistry. Grottammare (Italy): ATEC; 2002:41-50.

70. Colo G D, Zambito Y, Zaino C; Polymeric Enhancers of Mucosal Epithelia Permeability: Synthesis, Transepithelial PenetrationEnhancing Properties, Mechanism of Action, Safety Issues. J Pharm Sci. 2008; 97(5):662-1679.

71. Adv Drug Del Rev 2001; 91:S91-S101

2. Christian Kohlpaintner, Markus Schulte, Jürgen Falbe, Peter Lappe, Jürgen Weber (2005), "Aldehydes, Aliphatic", Ullmann's Thanou M, Verhoef J C, Junginger H E; Chitosan and its derivatives as intestinal absorption enhancers. Encyclopedia of Industrial Chemistry, Weinheim: Wiley-VCH, doi:10.1002/14356007.a01_321.pub2 
73. Mikos, A.G., In: Peppas, N.A., Eds,. Preparation Methods and Structure of Hydrogels, Hydrogels in Medicine and Pharmacy, Vol I, CRC Press, Boca Raton, FL, 986, 1.

74. Peppas, N.A. and Merrill, E.W., J. Appl. Polym. Sci., 1977, 21, 1763

75. Kofinas, P. Athanasssiou, V. and Merrill, E. W., Biomaterials, 1996, $17,1547$.

76. Merrill, E.W., Dennison, K.A. and Sung, C., Biomaterials, 1993, 14, 1117.

77. Stringer, J.L. and Peppas, N.A., J. Control. Release, 1996, 42, 195

78. Jabbari, E. and Nozari, S., Eur. Polym. J., 2000, 36, 2685

79. Hennink, W.E. and Nostrum, C.F., Adv. Drug Deliv. Rev., 2002, 54, 13

80. Dai, W.S. and Barbari, T.A., J. Membr. Science, 1999, 156, 67

81. Tabata, A. and Ikada, Y., Pharm. Res., 1989, 6, 422

82. Yamamoto, M., Tabata, Y., Hong, L., Miyamoto, S., Hashimoto, N. and Ikada, Y., J. Control. Release, 2000, 64, 133

83. Jameela, A. and Jayakrishnan, A., Biomaterials, 1995, 16, 769

84. Lopes M.A. and Felisberti, M.I., Biomaterials, 2003, 24, 1279

85. Gehrke, S.H., Uhden, L.H. and McBride, J.F., J. Control. Release, $1998,55,21$.
86. Coviello, T., Grassi, M., Rambone, G., Santucci, E., Carafa, M., Murtas, E., Riccieri, F. and Alhaique, F., J. Control. Release, 1999, 60,367 .

87. Eagland, D., Crowther, N. J. and Butler, C.J., Eur. Poly. J., 1994, 30, 767.

88. Lowman, A.M. and Peppas, N.A., Macromolecules , 1997, 30, 4659

89. Shu, X.Z. and Zhu, K.J., Int. J. Pharm., 2002, 233, 217

90. Ko, J.A., Park, H.J., Hwang, S.J., Park, J.B. and Lee, J.S., Int. J. Pharm., 2002, 249, 165

91. Berger, J., Reist, M., Mayer, J.M., Felt, O., Peppas, N.A. and Gurny, R., Eur. J. Pharm. Biopharm., 2004, 57, 1.

92. Torre, P.M., Enobakhare, Y., Torrado, G. and Torrado, S., Biomaterials , 2003, 24, 1499

93. Noble, L., Gray, A.I., Sadiq, L. and Uchegbu, I.F., Int, J. Pharm., 1999, 192, 173 Noble, L., Gray, A.I., Sadiq, L. and Uchegbu, I.F., Int, J. Pharm., 1999, 192, 173

94. Zhang Y. X., F. P. Wu, M. Z. Li, E. J. Wang, Polymer 46 (2005) 7695-7700.

95. Galeska, T. K. Kim, S. D. Patil, U. Bhardwaj, D. Chattopadhyay, Papadimitrakopoulos AAPS Journal 7 (2005) 231-240.

96. Lynch, P. de Gregorio, K. A. Dawson, J. Phy. Chem. B 109, 2005, 6257-6261. 